\title{
JOINING PARTS FROM SHAPE-MEMORY ALLOY OF CU-Al SYSTEM AND STRUCTURAL METALS BY ARC-CONTACT WELDING
}

\author{
B.E. PATON ${ }^{1}$, D.M. KALEKO ${ }^{1}$, S.N. KEDROVSKY ${ }^{2}$, Yu.N. KOVAL ${ }^{2}$, \\ L.M. NEGANOV ${ }^{2}$ and V.N. SLEPCHENKO ${ }^{2}$ \\ ${ }^{1}$ E.O. Paton Electric Welding Institute, NASU \\ 11 Kazimir Malevich Str., 03680, Kiev, Ukraine. E-mail: office@paton.kiev.ua \\ ${ }^{2}$ G.V. Kurdyumov Institute for Metal Physics, NASU \\ 36 Acad. Vernadsky Blvd., 03680, Kiev, Ukraine. E-mail: metal@imp.kiev.ua
}

\begin{abstract}
Shape-memory alloys changing part configuration at heating, as well as preserving their elasticity at up to $8-10 \%$ deformation, are becoming ever wider applied in industrial products and apparatuses as thermally-activated elements. Commercial application of alloys of $\mathrm{Cu}-\mathrm{Al}$ system instead of well-studied alloy of Ti-Ni system (nitinol) allows lowering product cost and expanding the application area up to high temperatures (about $400{ }^{\circ} \mathrm{C}$ ). Widening the range of products with elements from shape-memory alloys requires studying the possibility of joining metals of this system with structural metals, in particular, with stud-type fasteners. Proceeding from available experience, joints of studs from low-carbon steel of St.3 grade and 12Kh18N9T stainless steel, as well as L63 brass and AMg3 aluminium alloy produced by the methods of arc-contact welding by a capacitor discharge and by DC pulse were studied. Good results were obtained at capacitor welding of studs from the above materials, except for AMg3. The latter is attributable to greater mismatch of thermophysical properties of the metals joined. In DC welding, strong joints were produced only with studs from St.3 steel, because of greater time of welding. It is shown that pulsed welding methods enable preserving functional properties of parts from shape-memory alloys. Inhomogeneity of butt metal structure was found in dissimilar metal welding, which is attributable to short-time existence of the melt (incomplete mixing) and heterogeneity and non-simultaneity of joint cluster solidification. A positive consequence of that is absence of brittle intermetallics of $\mathrm{FeAl}_{3}$ type in the butt and preservation of ductility at deformation of joints with steel studs. 5 Ref., 1 Table, 9 Figures.
\end{abstract}

Ke y w or d s : shape-memory alloys, copper-aluminium alloys, arc-contact welding, structural materials, thermoelastic martensitic transformation

Modern technology is increasingly interested in application of materials with special properties, allowing development of devices, self-activating at the change of external conditions. Specific characteristics of such materials enable simplifying the design, and consequently, improving the operating reliability of machine activators. Such materials include, in particular, shape-memory alloys (SMA).

These alloys attract growing interest in different sectors of industry, medicine and culture, owing to the possibility of practical utilization of their thermoelastic characteristic, namely their ability to recover the preset shape at heating, after deformation in the cold state. In addition to thermoelasticity (form change under the impact of stresses, arising at crystallographic transformations), these alloys are also characterized by widely applied properties of superelasticity, namely preservation of elastic properties at relatively high deformations.

From the large number of known shape-memory alloys, the best studied and the most widely accepted now are alloys based on two systems, namely $\mathrm{Ti}-\mathrm{Ni}$ and $\mathrm{Cu}-\mathrm{Al}$. Each of them has its advantages and dis- advantages. Nitinol meets the requirements of medical applications better than do other alloys, namely it has high corrosion resistance, bioinertness and biocompatibility, as well as good mechanical properties (yield point is higher than $1 \mathrm{GPa}$, elastic deformation is up to $8 \%$, modulus of elasticity is about $70 \mathrm{MPa}$ ). At the same time, in most of non-medical applications less expensive copper-based alloys can be used, the technology of manufacturing and heat treatment of which is well-known. In addition to relatively low cost, copper-aluminium SMA, compared to nitinol, have higher limit temperature range of martensitic transformations that allows them to be used in devices, operating at high temperatures, for instance, in automatic fire extinguishing systems or in thermal plants of the type of furnaces, boilers or steam lines.

Industrial application of any materials, including SMA, requires solving the problems of joining them to each other or to other materials. Earlier [1, 2], we showed that characteristics of SMA of Ni-Ti or $\mathrm{Cu}-$ $\mathrm{Al}$ systems are preserved at pulse welding, and, therefore, this class of welding processes can be applied for 
joining these alloys, when used in thermally-activated structures.

It should be noted that the earlier considered welding methods and characteristic small dimensions of the samples allowed limiting current pulse duration to several milliseconds. This was convenient to produce welded joints in medical products and in instrument-making. However, application of copper-aluminium alloy in power engineering requires increasing the welded cross-section, and duration of welding heating and energy input, respectively.

This work is a study of the possibility of joining plates from SMA of $\mathrm{Cu}-\mathrm{Al}$ system to fasteners in the form of studs from structural alloys of different grades. The complexity of the problem was determined not only by behaviour of the alloy with shape-memory effect in the joint, but also by metallurgical compatibility of dissimilar metals, including combinations of iron alloys and non-ferrous metals. Traditional stud welding techniques, namely capacitor-discharge welding («contact» and «gap» methods) and DC arc welding are also considered [3]. Experiments on capacitor stud welding were performed in K-747MB machine [4], arc welding experiments were conducted in GLV 650 machine of HBS Company (Germany).

Capacitor stud welding. At selection of the mode of capacitor stud welding the variable parameters were capacitor capacitance, their charging voltage, lift height (in welding by «gap» method) and upset force (Table). Results of rupture testing showed that it was not possible to produce strong joints with all the materials. This pertains, in particular, to welding studs from AMg3 aluminium alloy. Strong and stable joints were produced only with studs from this alloy of not more than M3 diameter by «contact» welding method. In standard stud, in keeping with ISO 13918, the ratio of joint area (area of the flange at the stud end to be welded) to stud cross-sectional area is maximum for M3* (Figure 3). Presence of a flange on the stud at capacitor welding is due to the need to increase the joint strength up to that of base metal without increasing the energy required to create a reinforcement around the stud body. Lowering of welding current enables capacitor welding of studs to a thin sheet, preservation of decorative or functional coating on the sheet reverse side and welding of dissimilar metals.

At determination of welding mode, providing strong welded joints, correspondence of welded samples quality to the condition of fracture running across the stud body, was verified by a rapid method: stud bending in keeping with ISO Standard 14555.
Modes of welding different studs to sheet material from $\mathrm{Cu}-\mathrm{Al}$ system alloys

\begin{tabular}{|c|c|c|c|c|c|}
\hline Stud material & $\begin{array}{c}\text { Threaded } \\
\text { stud }\end{array}$ & $\begin{array}{c}\text { Capacitor } \\
\text { capaci- } \\
\text { tance, } \\
\mathrm{mF}\end{array}$ & \begin{tabular}{|c|}
$\begin{array}{c}\text { Capacitor } \\
\text { charging } \\
\text { voltage, } \\
\text { V }\end{array}$ \\
\end{tabular} & $\begin{array}{c}\text { Upset } \\
\text { force, } \mathrm{N}\end{array}$ & $\begin{array}{l}\text { Lift } \\
\text { height, } \\
\text { mm }\end{array}$ \\
\hline \multicolumn{6}{|c|}{ «Contact» welding } \\
\hline \multirow{3}{*}{ St.3 steel } & M3 & 96 & 60 & 15 & - \\
\hline & M6 & 96 & 100 & 15 & - \\
\hline & M8 & 96 & 150 & 15 & - \\
\hline \multirow{3}{*}{ 12Kh18N9T steel } & M3 & 72 & 75 & 15 & - \\
\hline & M6 & 96 & 125 & 10 & - \\
\hline & M8 & 96 & 150 & 10 & - \\
\hline \multirow{3}{*}{ L63 brass } & M3 & 48 & 100 & 10 & - \\
\hline & M6 & 60 & 125 & 10 & - \\
\hline & M8 & 96 & 175 & 10 & - \\
\hline AMg3 alloy & M3 & 72 & 80 & 15 & - \\
\hline \multicolumn{6}{|c|}{ «Gap» welding } \\
\hline \multirow{2}{*}{ St.3 steel } & M3 & 96 & 80 & - & 3 \\
\hline & M8 & 96 & 150 & - & 3 \\
\hline \multirow{2}{*}{ L63 brass } & M3 & 36 & 75 & - & 2 \\
\hline & M6 & 72 & 125 & - & 2 \\
\hline
\end{tabular}

Dependence of tensile strength of joints on welding mode parameters was studied on studs of M6 diameter. Results of these measurements are shown in Figure 2.

Influence of capacitor capacitance on joint strength in «contact» welding was determined at constant value of capacitor charging voltage, which corresponds to optimum value given in the Table, namely, $100 \mathrm{~V}$ for St. 3 steel, $125 \mathrm{~V}$ - for studs from $12 \mathrm{Kh} 18 \mathrm{~N} 9 \mathrm{~T}$ steel and L63 brass. Analysis of curves of rupture force dependence on capacitor capacitance (Figure 2, a) showed that for steel studs at maximum capacitor capacitance the welding mode still remains energetically unexhausted, but the achieved strength already corresponds to specific characteristics of the material. At the same time, welding studs from lower-melting

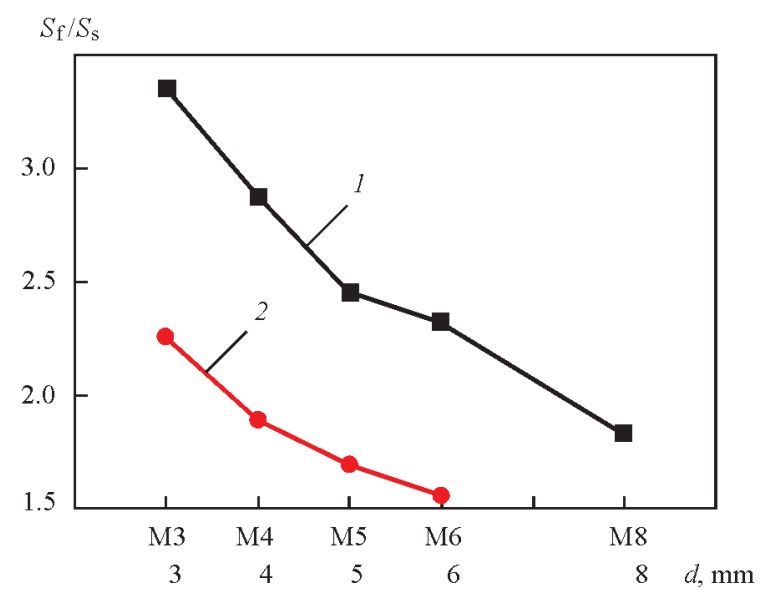

Figure 1. Standard ratio of the area of flange end face on the stud to section of threaded (1) and smooth (2) studs

${ }^{*}$ That is most probably related to conditions of stud manufacturing by cold upset forging. 

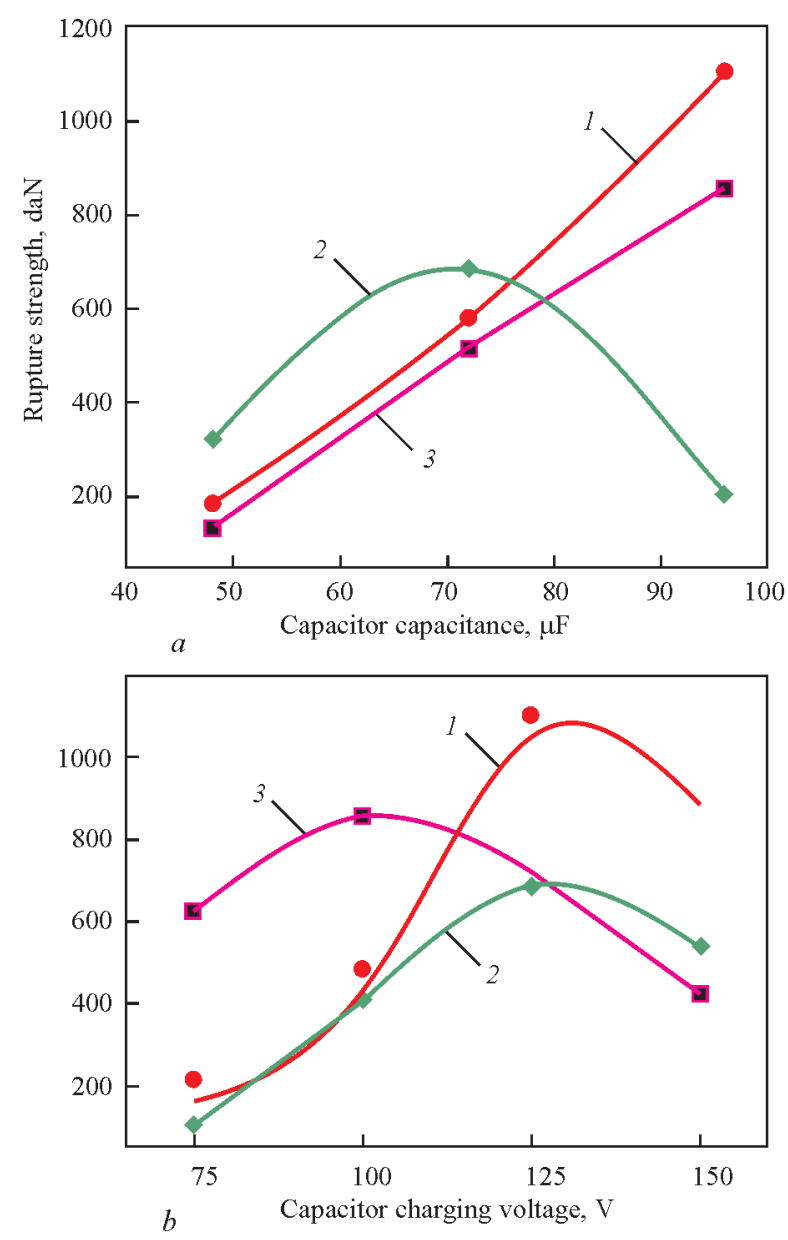

Figure 2. Dependence of strength of welded joints of M6 studs from different metals with plates from SMA of $\mathrm{Cu}-\mathrm{Al}$ system on capacitance $(a)$ and charging voltage $(b)$ of capacitors: 1 12Kh18N9T steel; 2 - L63 brass; 3 - St.3 steel

brass with exceeding the optimum value of energy, accumulated in the capacitors, leads to lowering of sample strength. As shown by visual analysis, this is due to melting out of a considerable part of the flange being welded. At tension, fracture runs across the flange body with stud tearing out.

As the energy accumulated in the capacitors has a quadratic dependence on charging voltage, influence of the latter is more significant than that of the capacitance values. This is illustrated by Figure 2, $b$. Determination of joint strength dependence on capacitor charging voltage was performed with M3 studs at capacitor capacitance found to be the optimum one (Table). The curves and sample examination showed that at a low capacitor charge the stored energy is insufficient for melting the entire abutted surface of the flange at the stud end face. Here, an undercut is preserved in the welded joint at the flange periphery. When the optimum value of stored energy in the butt is exceeded, pores are formed, as shown by fracture analysis, reducing the joint area. Visual analysis revealed simultaneous intensification of liquid overheated metal splashing, that also reduces the joint area and creates a slot between the stud and the sheet.

Upset force is one of the determining parameters of the mode of capacitor stud welding. In welding by the «contact» method, the results of which are discussed below, and in which upsetting is performed before arc excitation by explosion of a thin protrusion at the stud end face, the force is determined by the time of stud holding at discharge current (Figure 3). The influence of contact resistance on duration of heating the exploding protrusion (section 1) is clearly seen in voltage oscillogram. Comparison of oscillograms shows that the delay of arc excitation (Figure 4,b) leads to shorter duration of arc stage of the discharge (section II in voltage curve).

Shown oscillograms also demonstrate lowering of amplitude value of current and voltage between the parts being welded (arc electrodes) at increase of pressure of welding head spring. These changes are caused by counter-action of spring upsetting pressure and exploding protrusion vapour pressure. Increase of vapour pressure at protrusion overheating by prolonged current passage leads to greater electric resistance of the arc gap (comparable with discharge circuit resistance) that causes current lowering, whereas increase of spring pressure reduces the arc length, while changing its voltage.

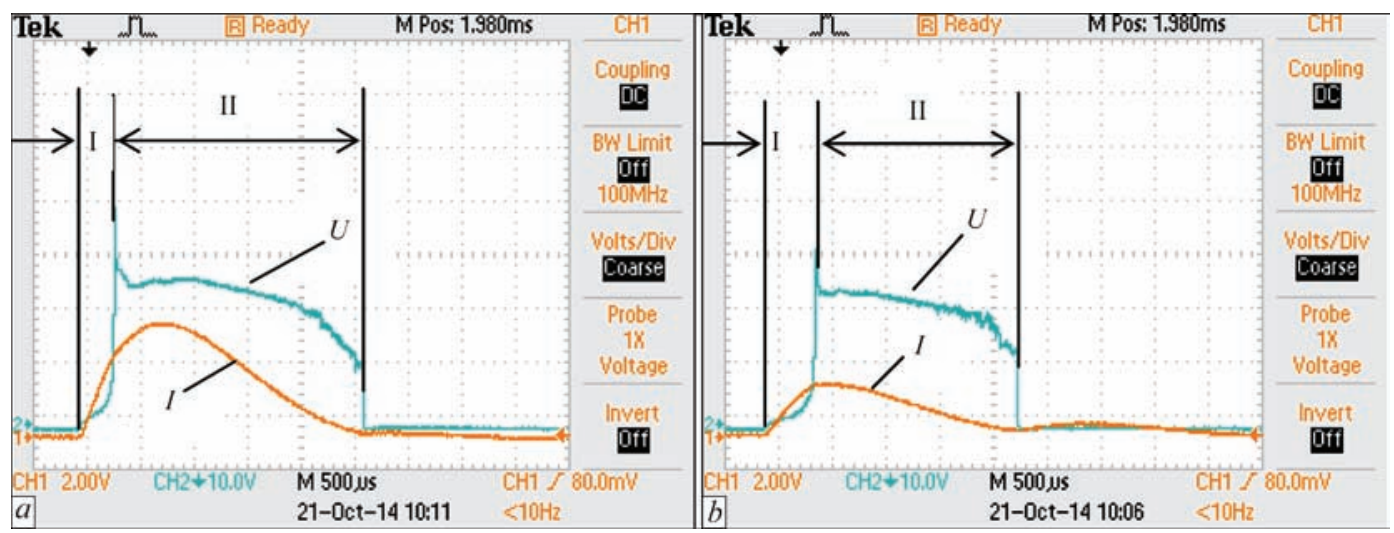

Figure 3. Oscillograms of current $I$ and voltage $U$ between the parts being welded during welding M8 studs from stainless steel by «contact» method with spring pressure of $50(a)$ and $60 \mathrm{~N}(b)$ (96 mF capacitor capacitance, $150 \mathrm{~V}$ charging voltage) 


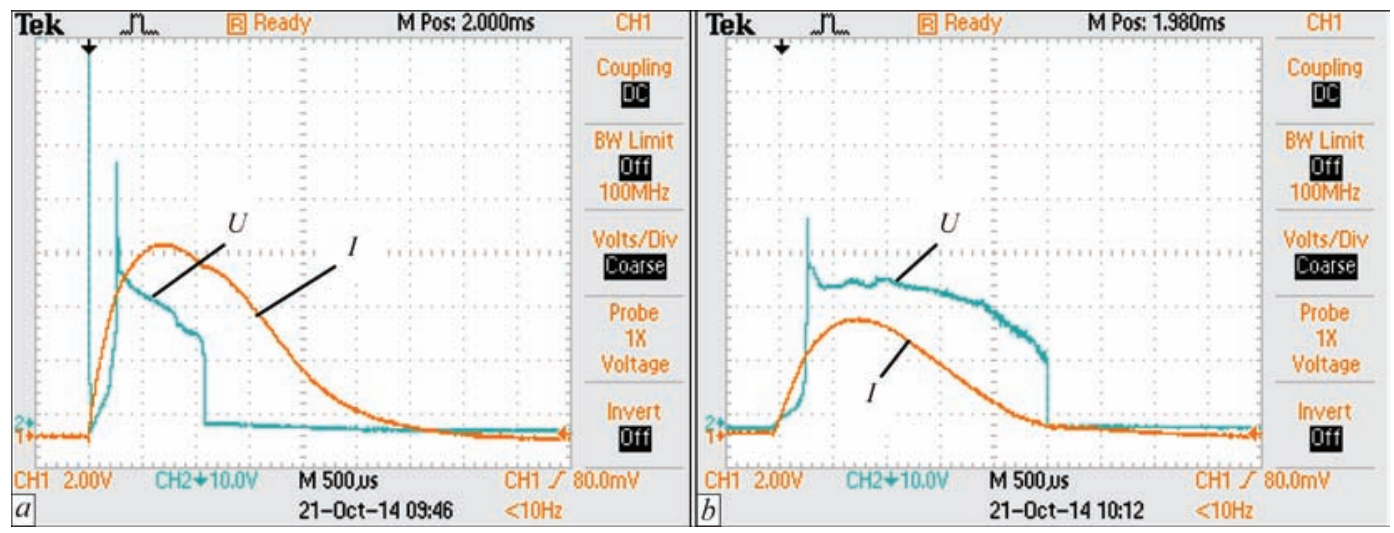

Figure 4. Oscillograms of welding current $I$ and arc voltage $U$ at capacitor welding of M8 studs from low-carbon steel by «gap» (a) and «contact» $(b)$ methods ( $96 \mathrm{mF}$ capacitor capacitance, $150 \mathrm{~V}$ charging voltage)

The next experimental series belongs to arc-contact capacitor stud welding by «gap» method. This method differs from the earlier considered one by that the discharge current is switched on when the stud, which has been removed from the sheet at the start of the welding process (in de-energized state), comes into contact with the sheet under the impact of welding device spring. At this moment current loop is closed and burning-out of roughnesses begins at the tip of the thin protrusion of the stud.

The main features of the processes of arc excitation at capacitor stud welding and arc excitation by exploding protrusion are demonstrated by oscillograms of welding current and arc voltage (Figure 4).

First, in welding by the «gap» method the stage of arc excitation (arc gap formation) is shorter than in welding by «contact» method. This can be judged by a delay of voltage rise, accompanying protrusion «explosion». In the given oscillograms this difference is about $20 \mathrm{~ms}$ at $3 \mathrm{~mm}$ initial gap*. Note that voltage surge at the moment of arc excitation in «gap» welding is higher than that in "contact» welding, as the initial volume of plasma is smaller in the first case than it is in the second case, and, more over, it is pressed by a mobile clamp to the stud. This leads to greater resistance at the moment of arc excitation, which drops quickly to a characteristic resistance value at regular voltage of the arc discharge.

Secondly, duration of the discharge stage of the arc in «gap» welding is much smaller that it is in «contact» welding. This feature is attributable to arc excitation at burning out of microroughnesses in the point of contact in the first variant and protrusion «explosion» in the second one. At protrusion evaporation, vapour pressure is greater than at arc running between the protrusion and the sheet that leads to greater arc length, as follows from the above-said. This assumption is confirmed by higher arc voltage in Figure 4, $b$. In addition, arcing time also influences the inertia of movable mass of welding device that counteracts metal vapour pressure. Therefore, in welding with a moving stud by «gap» method, the arc stage of the discharge is shorter than that in «contact» welding, when «hanging» of movable mass occurs at the start of the process, and, thus, arcing time is increased. Arc shortening in «gap» welding and respective reduction of discharge loop resistance lead to increase of amplitude value of current.

Peculiarities of processes of capacitor welding of studs by different methods determined the limited success of welding studs to sheets from SMA of $\mathrm{Cu}-\mathrm{Al}$ system by «gap» method. As shown by the Table, this method allowed welding only studs from low-carbon steel in the M3-M8 diameter range that corresponds to limit capacity of K747MB machine, as well as those from brass of M3 and M6 diameter. In experiments with other metals undercuts and cracks in butt joint metal could not be avoided.

Known are the difficulties of joining iron alloys to aluminium alloys, associated with butt metal embrittlement as a result of formation of $\mathrm{Fe}-\mathrm{Al}$ intermetallics of different stoichiometric composition. However, at impact bend testing to ISO 14555 of our joints of steel studs with an alloy of $\mathrm{Cu}-\mathrm{Al}$ system, the samples withstood plastic bending through $90^{\circ}$. No other intermetallic inclusions were revealed, either. Apparently, such compounds are absent, or they are scattered through the matrix in the form of dispersed particles, not detectable by metallographic analysis, that is confirmed also by durometry investigations in the butt joint area.

Typical microstructure of the zone of welding steel studs to a sheet of SMA of $\mathrm{Cu}-\mathrm{Al}$ system is shown

\footnotetext{
*Initial gap value influences the force at which roughnesses at the end face are deformed. The greater the gap, the greater the force of compression, and the lower the contact resistance, which causes thermal excitation of the arc at roughnesses evaporation from the end face.
} 


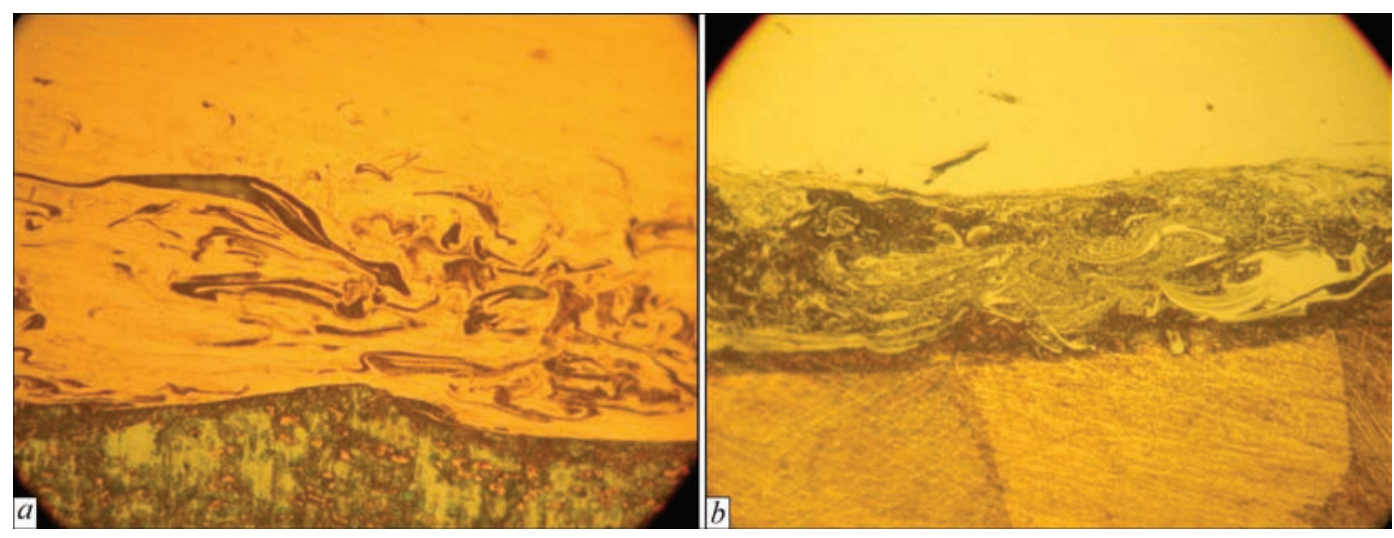

Figure 5. Microstructure $(\times 500)$ of joints of M6 studs from low-carbon $(a)$ and stainless $(b)$ steel

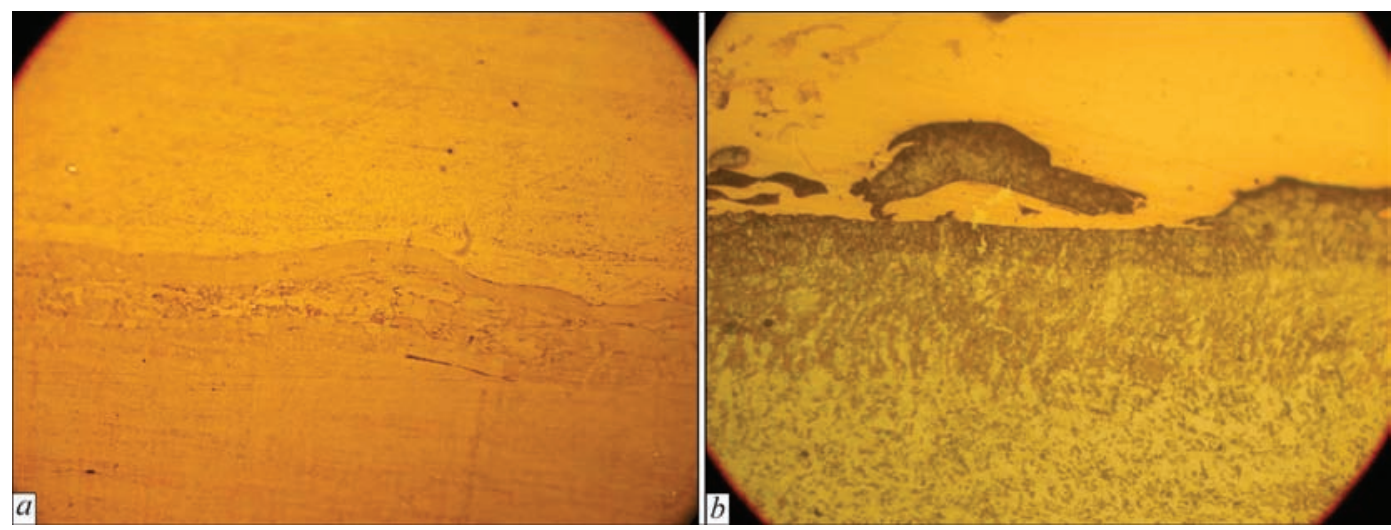

Figure 6. Microstructure $(\times 500)$ of joints of M6 studs from brass L63 (a) and aluminium alloy AMg3 (b)

in Figure 5. It is characterized by presence of a layer, in which molten metal of the stud is mixed with sheet metal (dark-coloured zone). As SMA melting temperature is lower (by almost $400{ }^{\circ} \mathrm{C}$ ) than that of stud material, the latter is the first to solidify, jamming SMA metal. This is also manifested in that the butt joint of St.3 steel with melting temperature of $1530{ }^{\circ} \mathrm{C}$, has less jammed alloy, than the butt joint of stainless steel with melting temperature of about $1400{ }^{\circ} \mathrm{C}$, closer to SMA melting temperature, which is about $1000^{\circ} \mathrm{C}$.

Microstructures of stud joints from metals, related to $\mathrm{Cu}-\mathrm{Al}$ alloy components, namely brass $\mathrm{L} 63$ and aluminium alloy AMg3, have less contrast (Figure 6). In view of closeness of melting temperatures, the metals being welded to each other, solidify in the butt almost simultaneously, so that only a small quantity of the low-melting phase is jammed. This is illustrated by comparison of microstructures of joints of L63 studs (Figure $6 a$ ), in which molten metal of both the joint elements solidified almost simultaneously, and those of AMg3 alloy (Figure 6,b) - a lower melting alloy than complex alloy of $\mathrm{Cu}-\mathrm{Al}$ system, so that the latter was preserved as an islet in the aluminium alloy. The given microstructure photos show that the joint surface is dense, without pores or other discontinuities.

DC welding of studs. Current value at capacitor stud welding is equal to several kiloamperes, while in
DC welding of the same stud cross-sections current value is not more than $1 \mathrm{kA}$. Duration of the process of arc-contact stud welding is more than an order of magnitude greater than capacitor welding time. As a result, each of these arc-contact welding processes has its applications.

Owing to short duration of the process, capacitor welding has its advantages, namely possibility of stud joining to a thin sheet with thickness to stud diameter ratio of 1:10 (in DC welding this ratio is 1:6 for up to M12 studs and 1:4 for larger diameter studs) and possibility of joining with parts having heat-sensitive coatings, for instance, those from polymer, layer paint or another decorative material. However, a disadvantage of this welding process, which is also related to short duration of the process, is the need for precisely keeping the perpendicularity of stud axis to the surface of the sheet, to which it is welded, within $7^{\circ}$. This, certainly, requires higher welder's qualifications, and limits operation efficiency.

The method of arc-contact stud welding by DC current is devoid of such a drawback to a certain extent.

Experiments were conducted with threaded studs from low-carbon steel St.3 and stainless steel $12 \mathrm{Kh} 18 \mathrm{~N} 9 \mathrm{~T}$, as well as aluminium alloy $\mathrm{AMg} 3$ of a standard shape, having a flange greater than the stud cross-section by a value given in the Table, which is tapered at the tip with apex angle of $165^{\circ}$. 

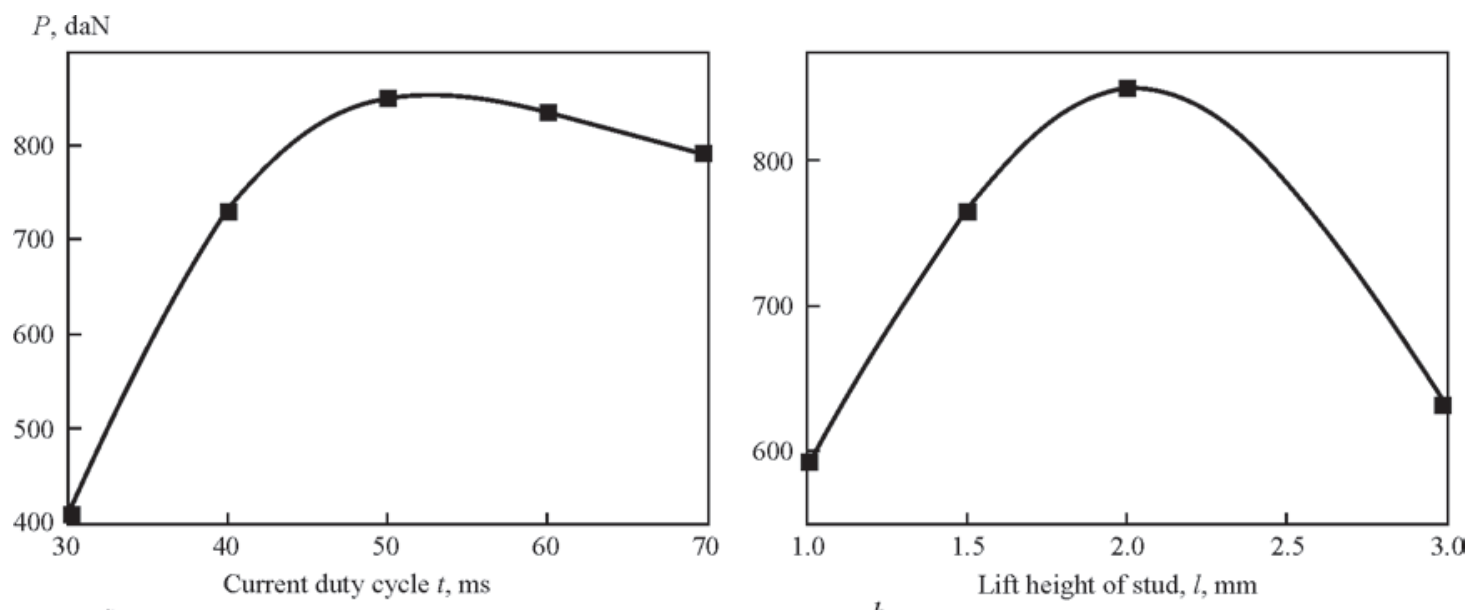

Figure 7. Influence of mode parameters of arc-contact welding of steel studs M6 to a sheet of SMA of Cu-Al system $8 \mathrm{~mm}$ thick on joint strength: $a-l=2 \mathrm{~mm} ; b-t=50 \mathrm{~ms}$

GLV machine, in which experiments were performed, does not allow adjusting welding current value, which nominally is equal to $650 \mathrm{~A}$, or its polarity, which is set as straight in the machine, so that the adjustable parameters were only welding current pulse duration and lift height of the stud. AMg3 studs were welded in argon, fed into the welding zone with $15 \mathrm{l} /$ min flow rate with pre-blowing for $10 \mathrm{~s}$. Joints were evaluated by impact bending and tensile strength, as well as by their appearance. Strong joints could only be obtained on St.3 steel studs.

Considering possible applications of joints with welded studs, their diameter was limited to M6 and M8, so that «short cycle» welding process was selected from all the possible variants of arc-contact stud welding, at which welding time is not more than $100 \mathrm{~ms}$.

Joints with M6 studs from AMg3 alloy failed in the welding area at bending through up to $10^{\circ}$ angle. Change of welding mode parameters in a broad range did not allow producing strong joints.

Analysis of fracture area led to the assumption that the cause for failed experiment is the mismatch of thermo-physical characteristics of materials being welded. Energy, sufficient for melting the stud surface, turned out to be insufficient for melting the sheet to a depth that provides a strong joint. If welding current duration is increased up to the value, sufficient for creating a satisfactory volume of molten metal on the sheet surface, then the flange on the stud being welded will be melted completely. This, certainly, lowers the joint strength. Subsequent experiments with steel studs confirmed this assumption.

Influence of welding mode parameters on welded joint strength was studied in welding M6 steel studs to sheet of $\delta=8 \mathrm{~mm}$. Obtained results in the form of graphs of joint strength dependence on duration of welding current pulse and lift height of stud at arc excitation stage are given in Figure 7. Analysis of the graphs is indicative of existence of a narrow optimum range of welding mode parameters, corresponding to strength properties of the joint, comparable with peel strength of the material. Deviation from them lowers joint strength, because of insufficient duration of the process (arcing time proportionally depends on the gap between the stud and sheet at the moment of the start of their drawing together and welding current switching on) or excess heating, leading to significant splashing of metal from the welding zone (Figure 8), pore formation and respective reduction of joint area.

Studying and analysis of results of impact bend testing of the joints in keeping with ISO 14555 Standard (Figure 8) and their comparison with the graph (Figure $7, a$ ) lead to the conclusion that the joints, which withstood this test, are not always equivalent to base metal in terms of strength.

Investigations of metallographic structure of samples of this composition, revealed non-uniformity of metal of joint solidification zone, namely presence of material in the base matrix, which solidified separately from the main mass (Figure 9). Generalizing these results with the above analysis (Figures 5 and 6) leads to the conclusion that the non-simultaneity of solidi-

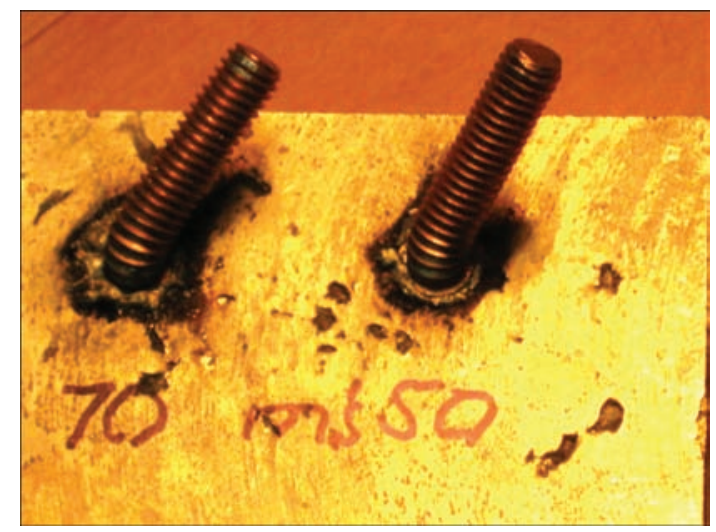

Figure 8. Samples of welding M6 steel studs with different heating duration 


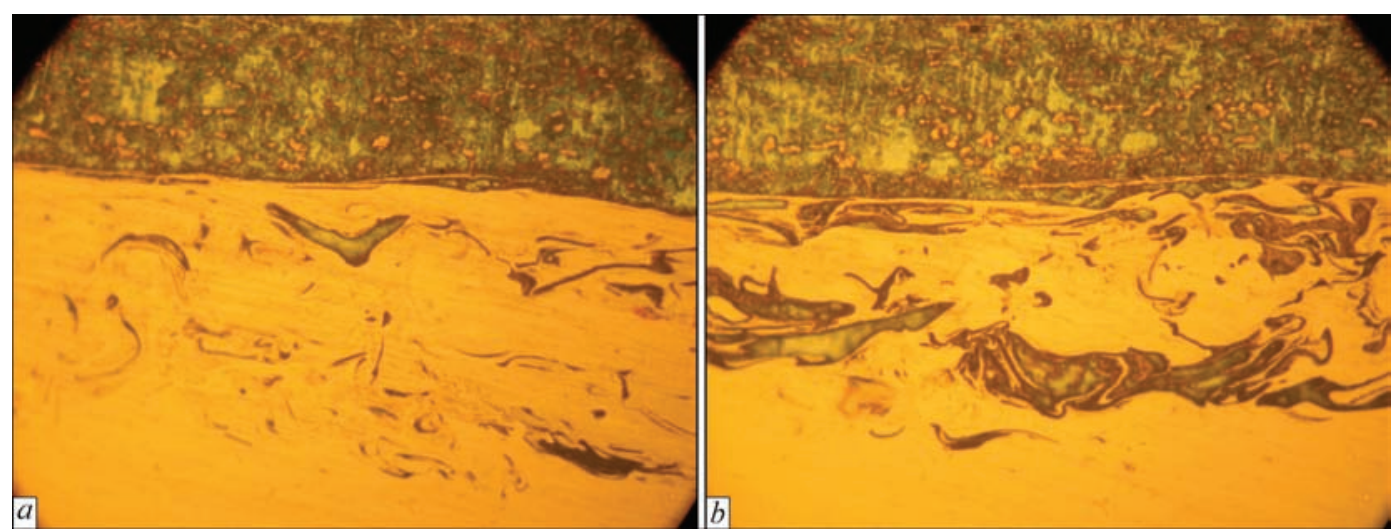

Figure 9. Microstructure $(\times 500)$ of zone welding of M6 stud from low-carbon steel with an alloy of Cu-Al system (below). Duration of welding current pulse of $50(a)$ and $70(b) \mathrm{ms}$

fication of materials being joined is typical for pulsed arc-contact welding of dissimilar metals. At increase of welding time, the joint zone becomes more heterogeneous due to its enrichment in the steel component (Figure 9, b).

Studying fractures of joints of steel studs with copper-aluminium alloy showed the ductile nature of the fracture. This is indicative of the fact that no brittle intermetallics form in pulsed welding mode. As shown by microstructural analysis of arc-contact welded joints, the HAZ, the size of which was determined by refinement of copper-aluminium alloy grains [5], is not more than $0.2 \mathrm{~mm}$. Preservation of the structure of the main bulk of SMA, as shown by earlier research [2], also ensures preservation of functional characteristics of the weldment.

\section{Conclusions}

1. Two methods of arc-contact welding, namely by capacitor discharge and by direct current, known as capacitor and arc stud welding, were tested for joining fasteners from steel and non-ferrous metals to complex alloy of $\mathrm{Cu}-\mathrm{Al}$ system.

2. Studying strength properties and metallographic structure showed that pulsed methods of arc-contact welding provide strong joints of fasteners in dissimilar combination with an alloy of $\mathrm{Cu}-\mathrm{Al}$ system, characterized by shape-memory effect. Owing to short duration of welding, the alloy preserves its functional characteristics. This enables an essential expansion of the range of products with these alloy, featuring high corrosion- and wear-resistance at relatively low lost.

3. Of the two variants of capacitor stud welding, it is preferable to apply the «contact» welding method for making dissimilar joints, which allows welding M3-M8 studs from L63 brass, low-carbon and stain- less steels owing to relatively low current and greater heating duration. Joints with more than $3 \mathrm{~mm}$ diameter studs from AMg3 could not be produced, because of a significant difference in melting temperatures.

4. At direct current arc-contact welding strong joints with SMA of $\mathrm{Cu}-\mathrm{Al}$ system could be obtained only with low-carbon steel studs, because of significant increase of welding time. Studs from non-ferrous metals and stainless steel melted out without preservation of the standard flange at the welded tip, which improves welded joint strength up to that of base metal.

5. Analysis of microstructure of arc-contact welded joints of dissimilar materials demonstrated heterogeneity of the welding zone. Inclusions of the lower-melting constituent are preserved in the matrix of the solidified phase. Metals being joined do not form a common structure, because of the short time of process and high cooling rate. Positive outcome of this process was manifested in ductility of fracture of joints with steel studs, owing to absence of brittle intermetallics of $\mathrm{FeAl}_{3}$ type in the butt joint.

1. Paton, B.E., Kaleko, D.M., Shevchenko, V.P. et al. (2006) Weldability of shape-memory alloys of Ni-Ti system. The Paton Welding J., 5, 2-7.

2. Paton, B.E., Kaleko, D.M., Kedrovsky, S.N. et al. (2015) Resistance welding of shape-memory copper-aluminium alloy. Ibid., 12, 2-7.

3. Lebedev, V.K., Kaleko, D.M., Chvertko, N.A. (1994) Development of technology and equipment for arc-contact welding of fastening parts to sheet and other surfaces of items. Svarochn. Proizvodstvo, 4, 14-16.

4. Kaleko, D.M., Kononets, B.I., Oseledko, N.N. et al. (1991) Unit K747MB for capacitor-discharge stud welding. Ibid., 6, 25-27.

5. Kaleko, D.M., Kedrovsky, S.N., Koval, Yu.N. et al. (2015) Pulsed capacitor-discharge welding of functional alloys based on $\mathrm{Cu}-\mathrm{Al}$ system and its influence on joint zone structure Metallofizika i Novejshie Tekhnologii, 37(12), 1663-1680. 